\title{
Validation of Reference Genes for qPCR Analysis of Resistance Training and Androgenic Anabolic Steroids on Hypothalamus, Adrenal Gland and Fat Tissue
}

\author{
Renan Pozzi, Leandro Fernandes, Bruno FA Calegare and Vânia D'Almeida* \\ Department of Psychobiology, Universidade Federal de São Paulo, UNIFESP, São Paulo, Brazil
}

\begin{abstract}
Background: Real-time quantitative Polymerase Chain Reaction ( $q P C R$ ) is a technique used for quantification of gene expression and the use of reference genes is very important to normalize the quantification results.

Aim: To validate the most suitable reference genes for resistance exercise training (REx) and use of nandrolone decanoate (DECA) in three different rat tissues.

Methods: A total of 40 adult male Wistar rats were distributed into four groups: exposed to vehicle three times per week (wk) (CT); eight wk of REx exposed to vehicle three times per wk (T); exposed to DECA three times per wk (D); eight wk of REx exposed to DECA three times per wk (TD). Stability of the following genes was evaluated: beta actin (Actb), alpha Tubulin (Tubulin), Glyceraldehyde-3-phosphate dehydrogenase (Gapdh), Hypoxanthine phosphoribosyltransferase-1 (Hprt1) and 18s Ribossomal RNA (18s) in hypothalamus, adrenal gland and mesenteric fat tissue using GeNorm, NormFinder and BestKeeper software.
\end{abstract}

Results: In hypothalamus and adrenal, all genes were suitable and none was rejected by statistical analysis; however, in fat tissue, Actb, Gapdh and Hprt1 genes were rejected by geNorm but not the others two software.

Conclusion: In hypothalamus and adrenal all selected genes analized were stable and can be used for qPCR gene expression analysis. However, in fat tissue we suggest the Tubulin gene as most stable gene.

Keywords: qPCR; Endogenous control gene; Resistance training; Androgenic anabolic steroids; Rats

Abbrevations: 18s: 18s Ribossomal RNA; AAS: Androgenic Anabolic Steroids; Actb: Beta Actin; Bp: Base Pair; Cq: Cycle Quantification; CT: Control Group; D: Nandrolone Group; DECA: Nandrolone Decanoate; Gapdh Glyceraldehyde-3-phosphate Dehydrogenase Hypoxanthine; Hprt1: Phosphoribosyltransferase-1; REx: Exercise Training; qPCR: Real-time Quantitative Polymerase Chain Reaction; T: Training group; TD: Training and Nandrolone Group; Tubulin: Alpha Tubulin; Wk: Week

\section{Introduction}

Real-time quantitative chain reaction (qPCR) relative or absolute analysis requires appropriated endogenous gene as reference gene for data normalization, which are known by: housekeeping gene, normalization gene, endogenous control gene, internal reference gene and suitable reference genes [1]. The reference gene is used to normalize the target gene expression and, for this reason, the incorrect choice of reference genes can alter final results [1].

Our group has validated reference genes for rat models of sleep deprivation [2] and hypoxia [3]. To our knowledge, there are no studies concerning validation of reference genes to analyze the effects of resistance exercise (REx) and androgenic anabolic steroids (AAS) use on gene expression. A good reference gene must show minimum variation of expression in all experimental groups or, in other words, its expression should not be influenced by experimental conditions. Considering the increasing number of exercise-related and/or anabolic steroids articles, validation of the most stable reference genes for qPCR was considered of interest.

AAS are manipulated compounds derivatives of testosterone, whose main function is to isolate the anabolic effect. They are important for the treatment of growth-related diseases, osteoporosis and anemia; however, when used at supraphysiological doses, they may produce side effects such as water retention, early closing of the bone epiphysis [4], aggressiveness [5,6], irritability, hostility, cognitive symptoms such as distractibility, forgetfulness and confusion, testicular atrophy, changes in the prostate and seminal vesicles, gynecomastia, growth changes [7], development of hepatic cysts [5], cardiovascular events such as myocardial infarction, cerebral infarction and pathological hypertrophy, increasing the likelihood of arrhythmias and stroke [8,9]. Thus, despite the abovementioned risks and being prohibited in many countries, athletes and amateur practitioners use supra physiological dosages of steroids to increase the performance and free fat mass.

Resistance exercise, commonly called weight training, is a type of exercise that has as main objective muscle strength gaining. The authors suggest that REx training is a valid strategy to improve blood pressure, insulin resistance, muscle mass and reduce circulating levels of inflammatory markers [10]. Furthermore, physiological and psychological benefits of REx are considered important in physical rehabilitation and treatment programs [11]. Therefore, a number of gene expression and molecular biological studies has been conducted in Rex training and steroids models, including ladder exercise models [1215]. There is a methodological gap, in which there is a lack of studies that identify the best reference gene in these areas of knowledge.

*Corresponding author: Vânia D'Almeida, Department of Psychobiology, Universidade Federal de São Paulo. Street Botucatu, 862-1st floor-Vila Clementino, São Paulo-SP-CEP: 04023062. Brazil, Tel: 55-11-21490155; E-mail: vaniadalmeida@uol.com.br

Received July 25, 2016; Accepted August 05, 2016; Published August 10, 2016

Citation: Pozzi R, Fernandes L, Calegare BFA, D’Almeida V (2016) Validation of Reference Genes for qPCR Analysis of Resistance Training and Androgenic Anabolic Steroids on Hypothalamus, Adrenal Gland and Fat Tissue. J Steroids Horm Sci 7: 180. doi: 10.4172/2157-7536.1000180

Copyright: () 2016 Pozzi R, et al. This is an open-access article distributed under the terms of the Creative Commons Attribution License, which permits unrestricted use, distribution, and reproduction in any medium, provided the original author and source are credited. 
It is known that there is no universal reference gene although Actb, Gapdh, Hprt1 and $\beta 2 M$, among others are the most commonly used [16]. There are no studies regarding reference genes in this area; therefore, the aim of this study was to validate reference genes for REx and AAS use in rat hypothalamus, adrenal gland and mesenteric fat tissue.

\section{Materials and Methods}

\section{Animals}

The study was performed using 40 male Wistar rats (10-wk-old; 300-350 g) from CEDEME (Centro de Desenvolvimento de Modelos Experimentais para Medicina e Biologia). Animals were maintained in the Department of Psychobiology facility (Universidade Federal de São Paulo). Room temperature was $22^{\circ} \mathrm{C}( \pm 1)$ with $12: 12 \mathrm{~h}$ light-dark cycle and access to food and water ad libitum was allowed. This study was conducted according to the Ethical of the use of Laboratory Animals Guidelines and its experimental protocol was approved by the Ethical Committee of Universidade Federal de São Paulo (\#177700/2013).

\section{Groups}

A total of 40 Wistar rats (10 wk old) was distributed into four groups: exposed to vehicle (peanut oil-subcutaneous administration $1 \mathrm{ml} / \mathrm{kg}$ ) 3 times/wk during $8 \mathrm{wk}(\mathrm{CT})$; resistance exercise during $8 \mathrm{wk}$ and exposed to vehicle (peanut oil-subcutaneous administration $1 \mathrm{~mL} / \mathrm{kg}$ ) 3x/wk during $8 \mathrm{wk}(\mathrm{T})$; exposed to DECA (subcutaneous administration $5 \mathrm{mg} / \mathrm{kg}$ ) 3 times/wk during $8 \mathrm{wk}$ (D); submitted to resistance exercise during $8 \mathrm{wk}$ and exposed to DECA (subcutaneous administration $5 \mathrm{mg} / \mathrm{kg}$ ) 3 times/wk during $8 \mathrm{wk}$ (TD).

\section{Exercise training and drug treatment}

The training protocol consisted of progressive REx, 5 times/wk during $8 \mathrm{wk}$ [adapted from 17-19]. A vertical ladder $(110 \mathrm{~cm}$ high by $18 \mathrm{~cm}$ wide, inclined at $80^{\circ}$ with $2 \mathrm{~cm}$ spacing between rungs) was used; at the top of the ladder there was a dark box $(20 \mathrm{~cm} \times 20 \mathrm{~cm} \times 20$ $\mathrm{cm})$, where the animal could rest between sets $(1 \mathrm{~min})$. Every week, the maximum carrying loading (MCL) was tested, so that the periodization could be determined (Table 1).

Supraphysiological nandrolone decanoate doses $(5 \mathrm{mg} / \mathrm{kg})$ were injected subcutaneously to each animal 3 times/wk for $8 \mathrm{wk}(15 \mathrm{mg} /$ $\mathrm{kg} / \mathrm{wk}$ ). This dosage was chosen for being equivalent to that used by athletes in physical exercise $[20,21]$. The peanut oil was used as vehicle at the same volume of DECA $(1 \mathrm{ml} / \mathrm{kg})$.

\section{Gene selection}

Exercise training and androgenic anabolic steroids affect several systems at cellular level; thus, candidate reference genes were selected

\begin{tabular}{|l|c|c|c|c|c|c|c|c|}
\hline \multicolumn{1}{|c|}{ Sessions/wk } & $\mathbf{1} \mathbf{w k}$ & $\mathbf{2} \mathbf{w k}$ & $\mathbf{3} \mathbf{w k}$ & $\mathbf{4} \mathbf{w k}^{\boldsymbol{*}}$ & $\mathbf{5} \mathbf{w k}^{\boldsymbol{*}}$ & $\mathbf{6} \mathbf{w k}^{\boldsymbol{*}}$ & $\mathbf{7} \mathbf{w k}^{\boldsymbol{*}}$ & $\mathbf{8} \mathbf{w k}^{\mathbf{*}}$ \\
\hline $1^{\text {st }}$ Session & 50 & 50 & 50 & 50 & 50 & 50 & 50 & 75 \\
\hline $2^{\text {nd }}$ Session & 50 & 50 & 50 & 50 & 50 & 50 & 75 & 75 \\
\hline $3^{\text {rd }}$ Session & 50 & 75 & 75 & 75 & 75 & 75 & 75 & 75 \\
\hline $4^{\text {th }}$ Session & 75 & 75 & 75 & 75 & 75 & 75 & 75 & 75 \\
\hline $5^{\text {th }}$ Session & 75 & 75 & 75 & 75 & 90 & 90 & 90 & 90 \\
\hline $6^{\text {th }}$ Session & 75 & 75 & 90 & 90 & 90 & 90 & 90 & 90 \\
\hline $7^{\text {th }}$ Session & & 90 & 90 & 90 & 100 & 100 & 100 & 100 \\
\hline $8^{\text {th }}$ Session & & & & 100 & 100 & 100 & 100 & 100 \\
\hline
\end{tabular}

$3^{\text {rd }}$ day of training, all session were done using $50 \%$ of MCL. $\# 4^{\text {th }}$ day, day-off. $¥ 4^{\text {th }}$ day, all session was done using $75 \%$ of MCL. MCL (Maximum Carrying Loading).

Table 1: Resistance training periodization in \% of MCL. among the most common reference genes from animal models in the literature. Reference genes selected were beta actin (Actb), alpha Tubulin (Tubulin), glyceraldehyde-3-phosphate dehydrogenase (Gapdh) hypoxanthine phosphoribosyltransferase-1 (Hprt1) and 18s ribossomal RNA (18s). Primers (Table 2) were designed and synthesized by IDT (Integrated DNA Technologies - www.idtdna.com) according to published Genbank sequences.

\section{RNA extraction, cDNA and qPCR}

After $24 \mathrm{~h}$ of experimental issue, the animals were euthanatized by decapitation between 07:00 am to 10:00 am. Fasting for at least 2 hours was established.

The hypothalamus and adrenal gland were collected and RNA extraction was performed using TRizol' Plus RNA Puification Kit (CAT\#12183-555 Ambion RNA, Life Technologies). Mesenteric fat tissue was also collected and total RNA was extracted using the RNeasy Plus Universal Mini Kit (CAT\#73404, QIAGEN), according to manufacturer's specifications. RNA was pretreated with DNAse I (2 $\mathrm{U} / \mu \mathrm{l}), 10 \mathrm{X}$ DNase I Buffer (100 mM Tris- $\mathrm{pH} 7.5,25 \mathrm{mM} \mathrm{MgCl}, 5$ $\mathrm{mM} \mathrm{CaCl}$ ) and incubated for $37^{\circ} \mathrm{C}$ for $30 \mathrm{sec}$ (Invitrogen) according to manufacturer's specifications. The $28 \mathrm{~S}$ and $18 \mathrm{~s}$ integrity of RNA was evaluated using agarose gel electrophoresis. RNA quantification was performed using spectrophotometry (NanoDrop) and purity was evaluated using two optimal wavelengths: ratio of 260/280 for nucleic acids $(1.8<$ sample $>2.2)$ and ratio of $260 / 230$ for organics contaminations $(1.8<$ sample $>2.2)$.

cDNAs were synthesized using $1 \mu \mathrm{g}$ of total RNA were placed in the presence of first mixture containing $0.5 \mu \mathrm{g} / \mu \mathrm{l}$ of Random Primers (Promega) and $3 \mathrm{mM}$ of $\mathrm{MgCl}_{2}$ (Promega), after that incubated at $70^{\circ} \mathrm{C}$ for 5 minutes. Then were placed in second mixture using Reaction Buffer 5X (Promega), $25 \mathrm{mM}$ of deoxyribonucleotide triphosphates (dNTP), $40 \mathrm{U} / \mu \mathrm{l}$ of RNase inhibitor (RNAsin) (Promega) and enzyme Improm II (Reverse Transcriptase) (Promega). The final volume was $20 \mu \mathrm{l}$. The conditions used for reverse transcription were as follows: $25^{\circ} \mathrm{C}$ for $5 \mathrm{~min}, 42^{\circ} \mathrm{C}$ for $60 \mathrm{~min}$ and $70^{\circ} \mathrm{C}$ for $15 \mathrm{~min}$, according to manufacturer's specifications.

qPCR was performed using SYBR Green PCR Master Mix (AppliedBiosystem, Warrington, UK) and StepOnePlus Real-Time PCR (AppliedBiosystem, Warrington, UK). Each reaction was performed using $2 \mu \mathrm{l}$ of cDNA, $6 \mu \mathrm{l}$ of $\mathrm{H}_{2} \mathrm{O}, 2 \mu \mathrm{l}$ of primers (forward and reverse at $0.5 \mu \mathrm{M}$ each) and $10 \mu \mathrm{l}$ SYBR green PCR Master Mix to the final volume of $20 \mu \mathrm{l}$. All samples were analyzed in duplicates and the average values were used. Design layout was: Holding stage: $3 \mathrm{~min}$ at $50^{\circ} \mathrm{C}$ and $10 \mathrm{~min}$ at $95^{\circ} \mathrm{C}$; Cycling stage (no of cycles: 40 ): $15 \mathrm{sec}$ at $95^{\circ} \mathrm{C}$ and $30 \mathrm{sec}$ at $60^{\circ} \mathrm{C}$. Melt curve stage: $15 \mathrm{sec}$ at $95^{\circ} \mathrm{C}$ and $60^{\circ}$ up $3^{\circ} \mathrm{C}$ each $15 \mathrm{sec}$ to $95^{\circ} \mathrm{C}$

\section{Data analysis}

GeNorm, NormFinder and BestKeeper: Three software were used to assess the stability of selected reference genes by different methods. All software are freely available to download permanently or as a demo for free for 14 days: geNorm (https://www.biogazelle.com/qbaseplus); NormFinder (http://moma.dk/normfinder-software); and

BestKeeper html\#download).

(http://www.gene-quantification.de/bestkeeper

The software geNorm uses the M-value as a stability variable, directly assessing linear scale expression quantities by using the standard curve and absolute quantification. The gene with the lower value of $\mathrm{M}$ 
Citation: Pozzi R, Fernandes L, Calegare BFA, D’Almeida V (2016) Validation of Reference Genes for qPCR Analysis of Resistance Training and Androgenic Anabolic Steroids on Hypothalamus, Adrenal Gland and Fat Tissue. J Steroids Horm Sci 7: 180. doi: 10.4172/2157-7536.1000180

Page 3 of 7

\begin{tabular}{|c|c|c|c|c|c|c|c|}
\hline Gene & ID GeneBank & Forward ( 5' - 3') & Reverse ( 5'-3') & Bp & Efficiency* & $\mathbf{T}^{\circ} \mathrm{C}$ & Primer [ ] \\
\hline Beta Actin & NM_031144.3 & GTGTGGATTGGTGGCTCTATC & CAGTCCGCCTAGAAGCATTT & 122 & $\begin{array}{l}\text { Hyphotalamus: } 97.8 \% \\
\text { Adrenal Gland: } 100.7 \% \\
\text { Fat Tissue: } 97.4 \%\end{array}$ & $60^{\circ} \mathrm{C}$ & $\begin{array}{l}\text { I: } 10 \mu \mathrm{M} \\
\text { F: } 0.5 \mu \mathrm{M}\end{array}$ \\
\hline Alpha Tubulin & NM_022298.1 & GACCTGGAACCCACAGTTATT & ATCTTCCTTGCCTGTGATGAG & 90 & $\begin{array}{l}\text { Hyphotalamus: } 97.3 \% \\
\text { Adrenal Gland: } 100.8 \% \\
\text { Fat Tissue: } 98.8 \%\end{array}$ & $60^{\circ} \mathrm{C}$ & $\begin{array}{l}\text { I: } 10 \mu \mathrm{M} \\
\text { F: } 0.5 \mu \mathrm{M}\end{array}$ \\
\hline Gapdh & NM_017008.4 & CATGGCCTTCCGTGTTCCTA & GCGGCATGTCAGATCCA & 55 & $\begin{array}{l}\text { Hyphotalamus: } 103.6 \% \\
\text { Adrenal Gland: } 102.6 \% \\
\text { Fat Tissue: } 101.6 \%\end{array}$ & $60^{\circ} \mathrm{C}$ & $\begin{array}{l}\text { I: } 10 \mu \mathrm{M} \\
\mathrm{F}: 0.5 \mu \mathrm{M}\end{array}$ \\
\hline Hprt1 & NM_012583 & GCGAAAGTGGAAAAGCCAAGT & GCCACATCAACAGGACTCTTGTAG & 76 & $\begin{array}{l}\text { Hyphotalamus: } 98.7 \% \\
\text { Adrenal Gland: } 98.0 \% \\
\text { Fat Tissue: } 99.0 \%\end{array}$ & $60^{\circ} \mathrm{C}^{*}$ & $\begin{array}{l}\text { I: } 10 \mu \mathrm{M} \\
\mathrm{F}: 0.5 \mu \mathrm{M}\end{array}$ \\
\hline $18 s$ & NR_046237 & CGGACAGGATTGACAGATTG & CAAATCGCTCCACCAACTAA1 & 83 & $\begin{array}{l}\text { Hyphotalamus: } 99.5 \% \\
\text { Adrenal Gland: } 94.0 \% \\
\text { Fat Tissue: } 97.8 \%\end{array}$ & $60^{\circ} \mathrm{C}$ & $\begin{array}{l}\mathrm{I}: 10 \mu \mathrm{M} \\
\mathrm{F}: 0.5 \mu \mathrm{M}\end{array}$ \\
\hline
\end{tabular}

Bp: Base pair; $\mathrm{T}^{\circ} \mathrm{C}$ : Temperature; Primer [ ]: Primer concentration in initial and final volume; I: Initial; F: Final. *In fat tissue, was the addition of stretch of 30 sec at $72^{\circ} \mathrm{C}$ for cycle. ${ }^{*}{ }^{2}>99$ was established. The amplification efficiency is calculated using the slope of the regression line in the standard curve.

Table 2: Reference genes ID and primers design.

is considered the "most stable". NormFinder also uses the values from absolute quantification to calculate stability, which indicates as Stability value the best candidate by the lower value. BestKeeper uses the HKG index which calculates the geometric average of the "most stable" reference genes by Repeated Pair-wise Correlation Analysis and p-value $(\mathrm{p}<0.05)$. GeNorm and Normfinder use $2^{-\Delta \mathrm{Ct}}$ and the BestKeeper uses Cq values for analysis.

\section{Results}

\section{Cycle quantification $(\mathrm{Cq})$ distribution}

The results related to fractional qPCR cycles are represented as follow: 1) Hypothalamus (Figure 1)-Gapdh showed the lowest standard deviation ( \pm 0.69$)$, followed by Actb $( \pm 1.27)$, Hprt1 ( \pm 1.35$)$, Tubulin ( \pm 1.69 ) and $18 s$ ( \pm 2.05$)$; 2) Adrenal gland (Figure 2)-results showed that Hprt1 had the lowest standard deviation $( \pm 0.96)$ followed by Gapdh $( \pm 1.25)$, Actb $( \pm 1.33)$, Tubulin $( \pm 1.87)$ and $18 s( \pm 1.92)$; 3$)$ Fat tissue (Figure 3), Gapdh showed the lowest variation Cqs ( \pm 1.52 ), followed by Hprt1 ( \pm 1.65$)$, Tubulin $( \pm 2.26), 18 s( \pm 2.48)$ and Actb $( \pm 2.83)$.

\section{BestKeeper analysis}

In hypothalamus, when comparing all experiments groups, CT $v s$. $\mathrm{D}, \mathrm{CT} v s$. D or CT vs. TD the most stable gene was 18 s gene followed by Actb, Tubulin, Hprt1 and Gapdh genes.

For adrenal gland, $18 \mathrm{~s}$ gene was the most stable when analyzing all groups, CT vs. D, and CT vs. T vs. D groups and the less stable was Hprt1. Rank sequence are available in Table 3.

In fat tissue when all groups were compared, as well as CT $v s . \mathrm{T}$, the most stable gene was Tubulin followed by Actb, 18s, Hprt1 and Gapdh. However, when CT vs. D and CT vs. TD were compared Tubulin remains the most stable gene and $H$ prt1 was rejected (Table 3).

\section{Normfinder analysis}

Analysis in Normfinder software showed that all genes in all groups were suitable, in other words, all genes showed stability values less than 0.15 [22], value considered by software. Moreover, this software showed best combination and stability value of two genes, e.g. in hypothalamus when compared all groups the best combination stability were $A c t b$ and $18 s$ wih $0.02 \mathrm{M}$-value. The other values are presented in Table 4 .

In hypothalamic tissue, the Actb gene was the most stable gene when compared all groups and CT vs. D groups. Moreover, when comparing

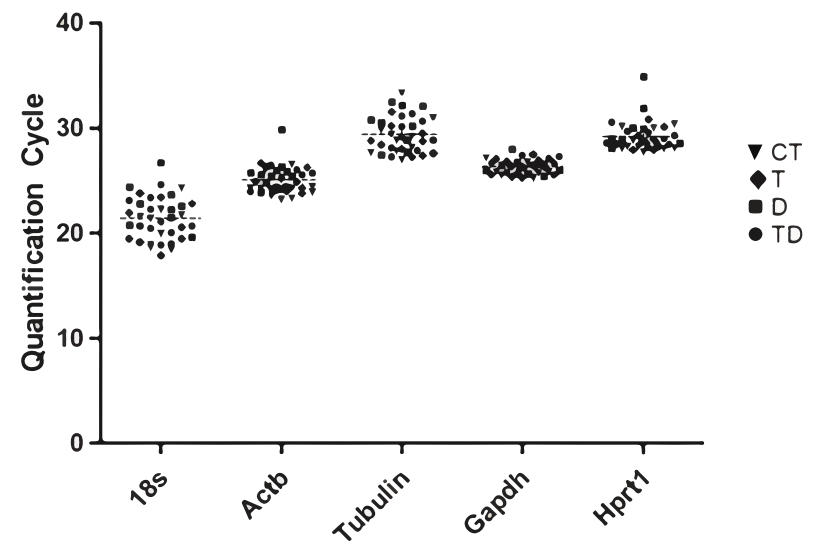

Figure 1: Hypothalamus quantification cycle distribution of reference genes expression from hypothalamus.

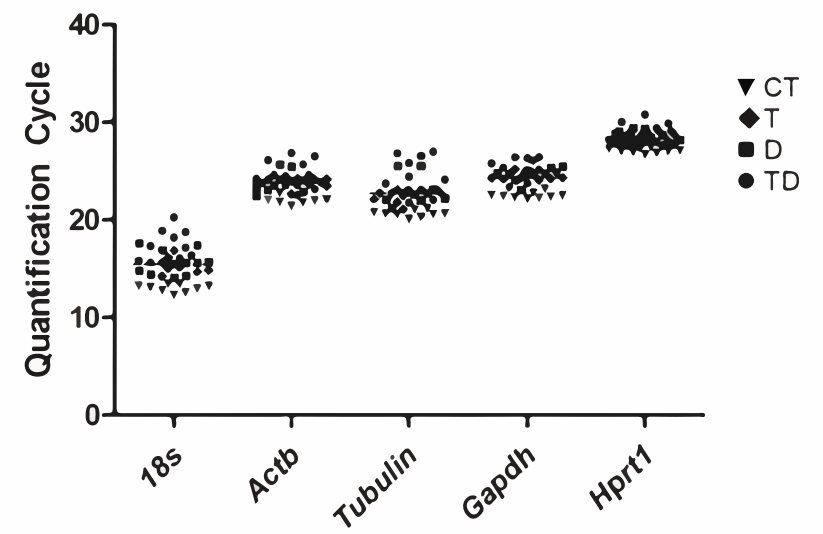

Figure 2: Adrenal gland quantification cycle distribution of reference genes expression from adrenal gland tissue.

CT vs. T and CT vs. TD groups, the Hprt1 gene was considered the most stable gene. When all groups were analyzed the following rank was obtained: Actb, 18s, Hprt1, Tubulin and Gapdh genes. When 
comparing CT vs. D groups, Actb, followed by $18 s$, Tubulin, Hprt1 and Gapdh genes. At CT vs. T and CT vs. TD groups, Hprt1, followed by $18 s$, Tubulin, Gapdh and Actb genes.

At adrenal gland, the ranks considering all groups and CT $v s$. TD groups were: 18s, followed by Tubulin, Gapdh, Actb and Hprt1 genes; for the CT vs. T groups: Tubulin, followed by Actb, 18s, Gapdh and Hprt1 genes; and for the CT vs. D groups: Tubulin, followed by $18 s$, Gapdh, Hprt1 and Actb genes.

The Tubulin gene was considered the most stable gene for fat tissue in all moments and Gapdh was the less stable gene, except in CT vs. D the Hprt1 gene was the less suitable gene (Table 4).

\section{GeNorm analysis}

Analysis made by software showed that in hypothalamus and adrenal gland all candidates are stable and could be used as reference genes but in mesenteric fat tissue, only Tubulin gene was stable in all analysis. The others genes (Hprt1, Actb, $18 s$ and Gapdh genes) had a $1.5 \mathrm{M}$-value and it, was not considered good reference genes at least one time.

In hypothalamus the most stable gene was $A c t b$ when comparing

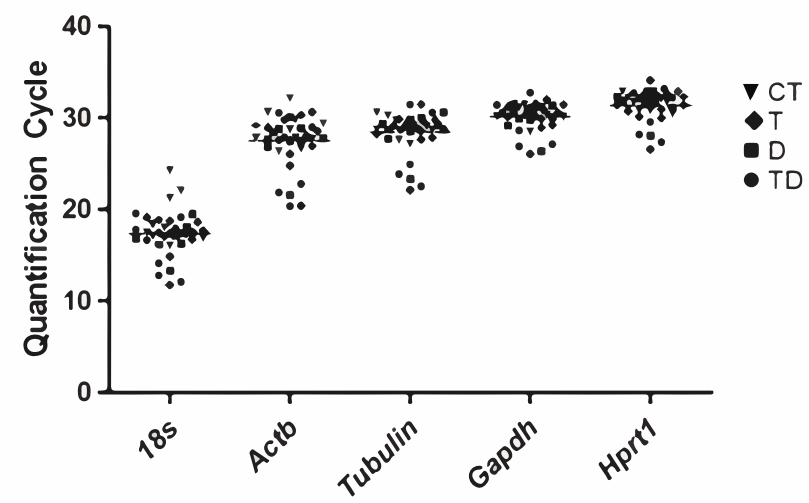

Figure 3: Fat tissue quantification cycle distribution of reference genes expression in fat mesenteric tissue. all groups, CT vs. D and CT vs. TD groups, followed by Hprt1, Tubulin, Gapdh and $18 s$ genes; and for the CT vs. T groups: Actb, followed by Hprt1, Gapdh, Tubulin and 18 s genes.

In adrenal gland, it was observed that the Hprt1 gene had the lower rank in all analysis. In all groups and CT vs. TD groups the Actb gene had the higher rank, following by Gapdh, Tubulin, 18s and Hprt1 genes. For the CT vs. T groups, Gapdh was the most stable gene, followed by Actb, Tubulin, 18s and Hprt1 genes; and for the CT vs. D, Gapdh was most suitable gene followed by Actb, 18s, Tubulin and Hprt1 genes.

Considering the mesenteric fat tissue the unique stable gene was the Tubulin in all analyzes. Hprt1 was stable when all groups and CT vs. T were compared. The other genes exceeded the $\mathrm{M}$-value allowed by the software (Table 5).

\section{Discussion}

To determination of relative expression of target gene in any assay there is a necessity of use a reference gene. Accordingly, the reference gene is usually an endogenous gene in which expression is unchanged regardless of intervention [23]. The use of reference genes is appropriated only if they are tested, normalized and considered stable, some authors believe that it is wrong any gene as reference gene without validating their suitability before running the experiment [24]. In this study, this amount of genes gives us an overview of what can be used in the experiments using AAS and REx.

A simple way to find the most stable reference gene is to analyze the Cq variation and use the one with the lowest variation between experimental groups [25]. However, there are specific software for this type of analysis; the most used in the literature are BestKeeper, Normfinder and geNorm [24]. To our knowledge, there are no studies investigating the most stable genes regarding exercise and anabolic steroids use; therefore, our study will contribute to a more adequate choice of reference genes for those experiments. We separate the analysis group to group to have a more complete analysis, so analyze all groups and then each separate factor, so there is an interpretation according to each intervention.

The analysis of more than one reference gene has been shown to be useful to validate the data, as well as to confirm the results. The authors suggest the use of three reference genes; if the results with the first

\begin{tabular}{|c|c|c|c|c|c|c|c|c|c|c|c|c|c|c|c|}
\hline \multirow{3}{*}{$\begin{array}{l}\text { Tissue } \\
\text { Groups } \\
\text { Gene }\end{array}$} & \multicolumn{5}{|c|}{ Hypothalamus } & \multicolumn{5}{|c|}{ Adrenal gland } & \multicolumn{5}{|c|}{ Mesenteric fat } \\
\hline & \multicolumn{5}{|c|}{ CT, D, T and TD } & \multicolumn{5}{|c|}{ CT, D, T and TD } & \multicolumn{5}{|c|}{ CT, D, T and TD } \\
\hline & $18 s$ & Actb & Tubulin & Hprt1 & Gapdh & $18 s$ & Tubulin & Actb & Gapdh & Hprt1 & Tubulin & Actb & $18 s$ & Hprt1 & Gapdh \\
\hline$r$ & 0.96 & 0.93 & 0.91 & 0.89 & 0.77 & 0.98 & 0.97 & 0.96 & 0.95 & 0.86 & 0.98 & 0.95 & 0.89 & 0.86 & 0.82 \\
\hline p-value & 0.001 & 0.001 & 0.001 & 0.001 & 0.001 & 0.001 & 0.001 & 0.001 & 0.001 & 0.001 & 0.001 & 0.001 & 0.001 & 0.001 & 0.001 \\
\hline Groups & \multicolumn{5}{|c|}{ CT vs. T } & \multicolumn{5}{|c|}{ CT vs. T } & \multicolumn{5}{|c|}{ CT vs. T } \\
\hline Gene & $18 \mathrm{~s}$ & Actb & Tubulin & Hprt1 & Gapdh & $18 s$ & Gapdh & Tubulin & Actb & Hprt1 & Tubulin & Actb & $18 s$ & Hprt1 & Gapdh \\
\hline$r$ & 0.94 & 0.91 & 0.88 & 0.88 & 0.68 & 0.98 & 0.98 & 0.96 & 0.95 & 0.87 & 0.96 & 0.92 & 0.85 & 0.78 & 0.64 \\
\hline p-value & 0.001 & 0.001 & 0.001 & 0.001 & 0.001 & 0.001 & 0.001 & 0.001 & 0.001 & 0.001 & 0.001 & 0.001 & 0.001 & 0.001 & 0.002 \\
\hline Groups & \multicolumn{5}{|c|}{ CT vs. D } & \multicolumn{5}{|c|}{ CT vs. D } & \multicolumn{5}{|c|}{ CT vs. D } \\
\hline Gene & $18 \mathrm{~s}$ & Actb & Tubulin & Hprt1 & Gapdh & $18 s$ & Tubulin & Gapdh & Actb & Hprt1 & Tubulin & Actb & $18 s$ & Gapdh & Hprt1 \\
\hline$r$ & 0.98 & 0.96 & 0.92 & 0.90 & 0.85 & 0.98 & 0.96 & 0.95 & 0.95 & 0.81 & 0.92 & 0.88 & 0.87 & 0.57 & 0.234 \\
\hline p-value & 0.001 & 0.001 & 0.001 & 0.001 & 0.001 & 0.001 & 0.001 & 0.001 & 0.001 & 0.001 & 0.001 & 0.001 & 0.001 & 0.008 & 0.321 \\
\hline Groups & \multicolumn{5}{|c|}{ CT vs. TD } & \multicolumn{5}{|c|}{ CT vs. TD } & \multicolumn{5}{|c|}{ CT vs. TD } \\
\hline Gene & $18 s$ & Tubulin & Actb & Hprt1 & Gapdh & $18 s$ & Tubulin & Actb & Gapdh & Hprt1 & Tubulin & Actb & $18 s$ & Gapdh & Hprt1* \\
\hline$r$ & 0.96 & 0.96 & 0.88 & 0.87 & 0.79 & 0.99 & 0.98 & 0.97 & 0.96 & 0.94 & 0.97 & 0.96 & 0.92 & 0.73 & 0.025 \\
\hline p-value & 0.001 & 0.001 & 0.001 & 0.001 & 0.001 & 0.001 & 0.001 & 0.001 & 0.001 & 0.001 & 0.001 & 0.001 & 0.001 & 0.00 & 0.922 \\
\hline
\end{tabular}

Data expressed as Pair-Wise Analysis Correlation ( $r$ ). Higher r correlation indicates the most stable gene. $p<0.05$ was used in Pearson Correlation. CT: Control Group; D: DECA Group; T: Training Group; TD: Training and DECA Exposed Group. *Result above the limit considered adequate by software analysis. 
Citation: Pozzi R, Fernandes L, Calegare BFA, D'Almeida V (2016) Validation of Reference Genes for qPCR Analysis of Resistance Training and Androgenic Anabolic Steroids on Hypothalamus, Adrenal Gland and Fat Tissue. J Steroids Horm Sci 7: 180. doi: 10.4172/2157-7536.1000180

Page 5 of 7

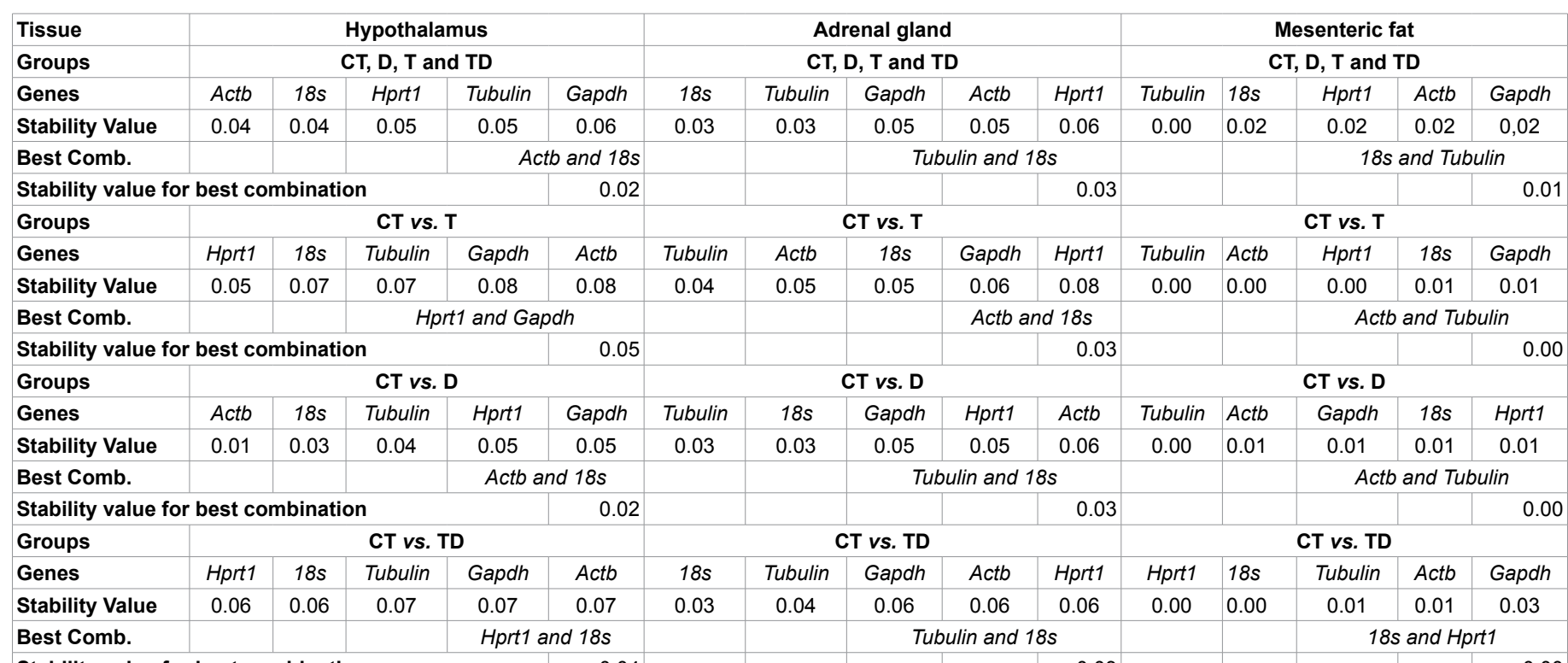

Stability value for best combination

0.04

0.03

0.00

Data expressed as Stability value. Lowest Stability value indicates most stable gene. Best Comb. (Best combination of two genes); CT: Control Group; D: DECA group; T: Training Group; TD: Training and DECA Exposed Group.

Table 4: Ranking of reference genes by the NormFinder software analysis.

\begin{tabular}{|c|c|c|c|c|c|c|c|c|c|c|c|c|c|c|c|}
\hline Tissue & \multicolumn{5}{|c|}{ Hypothalamus } & \multicolumn{5}{|c|}{ Adrenal gland } & \multicolumn{5}{|c|}{ Mesenteric fat } \\
\hline Groups & \multicolumn{5}{|c|}{ CT, D, T and TD } & \multicolumn{5}{|c|}{ CT, D, T and TD } & \multicolumn{5}{|c|}{ CT, D, T and TD } \\
\hline Genes & Actb & Hprt1 & Tubulin & Gapdh & $18 s$ & Actb & Gapdh & Tubulin & $18 s$ & Hprt1 & Tubulin & Hprt1 & Gapdh & Actb & $18 s$ \\
\hline M-Value & 0.95 & 1.02 & 1.14 & 1.23 & 1.26 & 0.75 & 0.77 & 0.87 & 0.88 & 0.99 & 1.21 & 1.39 & $1.50^{*}$ & $1.63^{*}$ & $1.79^{*}$ \\
\hline Groups & \multicolumn{5}{|c|}{ CT vs. T } & \multicolumn{5}{|c|}{ CT vs. T } & \multicolumn{5}{|c|}{ CT vs. T } \\
\hline Genes & Actb & Hprt1 & Gapdh & Tubulin & $18 s$ & Gapdh & Tubulin & Actb & $18 s$ & Hprt1 & Tubulin & Hprt1 & Gapdh & Actb & $18 s$ \\
\hline M-Value & 0.93 & 0.94 & 1.14 & 1.22 & 1.35 & 0.43 & 0.49 & 0.50 & 0.63 & 0.69 & 1.32 & $1.50^{*}$ & $1.69^{*}$ & $1.79^{*}$ & $2.01^{*}$ \\
\hline Groups & \multicolumn{5}{|c|}{ CT vs. D } & \multicolumn{5}{|c|}{ CT vs. D } & \multicolumn{5}{|c|}{ CT vs. D } \\
\hline Genes & Actb & Tubulin & Hprt1 & $18 s$ & Gapdh & Gapdh & Actb & Tubulin & $18 s$ & Hprt1 & Tubulin & Hprt1 & Gapdh & Actb & $18 s$ \\
\hline M-Value & 0.96 & 1.14 & 1.14 & 1.16 & 1.36 & 0.66 & 0.69 & 0.78 & 0.79 & 0.94 & 1.25 & 1.44 & $1.57^{*}$ & $1.63^{*}$ & $2.03^{*}$ \\
\hline Groups & \multicolumn{5}{|c|}{ CT vs. TD } & \multicolumn{5}{|c|}{ CT vs. TD } & \multicolumn{5}{|c|}{ CT vs. TD } \\
\hline Genes & $A c t b$ & Hprt1 & Tubulin & Gapdh & $18 s$ & Actb & Gapdh & Tubulin & $18 s$ & Hprt1 & Tubulin & Hprt1 & Gapdh & $A c t b$ & $18 s$ \\
\hline M-Value & 0.92 & 0.95 & 1.01 & 1.04 & 1.21 & 0.84 & 0.89 & 0.95 & 1.02 & 1.10 & 1.34 & $1.60^{*}$ & $1.72^{*}$ & $1.77^{*}$ & $2.07^{*}$ \\
\hline
\end{tabular}

Data expressed as M-Value. Lowest M-value indicates most stable gene. CT: Control Group; D: DECA Group; T: Training Group; TD: Training and DECA Exposed

Group. *Result above the limit considered adequate by software analysis.

Table 5: Ranking of reference genes by GeNorm software analysis.

two are different, a third reference gene must be used, and, if they are similar, it is not necessary to evaluate a third gene [26]. Dheda et al. [27] demonstrated after three experiments with different reference genes that the results can be significantly different from those obtained when an invalidated reference gene is used. This incorrect choice, therefore, results may be erroneous. The same authors also suggest strongly supporting the argument for validation of reference genes prior to their use.

We conducted a search in PubMed and selected 20 articles that investigated the effects of physical exercise and/or androgenic anabolic steroids on gene expression, through qPCR (SYBR Green method), in order to verify if there were common reference genes in these studies. Two groups used only the $18 s$ gene $[13,28]$, five used only Actb gene [29-33]. Other authors used the Cyclophilin gene [15,31] and eight authors used Gapdh as a reference gene in their studies [12,14,34-40]. Only three studies used more than one gene as internal control: Gapdh and large ribosomal protein P0 (RPLPO) genes [41]; Gapdh, Actb, Hprt1 and Cyclophilin gene [42]; the other authors used Ubiquitin $C$ gene as reference gene [43]. Considering the abovementioned articles, the most used reference genes were Gapdh and Actb in different species as human, monkey, rat, and mouse.

The results of the reference gene is controversial, some authors did not find stable results for Actb and Gapdh genes in injured muscle, the results were rejected by geNorm and BestKeeper [44]. In other study, also did not find stable results for Actb gene from hypothalamus of an obesity rat model [45]. Actb and Gapdh genes were rejected in muscle tissue by qBase, software that uses M-Value to analyze reference genes [26]. In our study, Actb and Gapdh genes were shown to be stable in all tissues analyzed by three different software; the only exception was for mesenteric fat analysis through geNorm, which rejected both genes, along with Hprt1.

In hypothalamus and adrenal gland, the three software used in our study showed similar results using different analyses (all groups together or separately, as in CT vs. T, CT vs. D or CT vs. TD). Many types of exercise and/or AAS could alter gene expression in different ways but, in most of our analyses, the values and ranking of genes were similar in all experimental groups. None of the genes were rejected by 
Citation: Pozzi R, Fernandes L, Calegare BFA, D’Almeida V (2016) Validation of Reference Genes for qPCR Analysis of Resistance Training and Androgenic Anabolic Steroids on Hypothalamus, Adrenal Gland and Fat Tissue. J Steroids Horm Sci 7: 180. doi: 10.4172/2157-7536.1000180

Page 6 of 7

any of the software; therefore, they are all suitable reference genes for qPCR analysis in rat hypothalamus and adrenal gland.

In mesenteric fat tissue, however, there were some discrepancies between results. All genes were stable and considered suitable as reference genes by Normfinder, but not by BestKeeper and geNorm analysis. GeNorm shows that the only stability gene was Tubulin (in all analysis) and when used Bestkepper software, the only exception was Hprt1 gene, showed above the limit considered adequate.

All software used to check the stability of genes are validated and considered replicated. Most often, results are repeatable despite using different calculations, as $\mathrm{M}$-value and pair-wise correlation. Whereas two of the three software considered all stable candidates and only geNorm considered only Tubulin as stable, we suggest that the best gene to be used of adipose tissue is indeed Tubulin, however, could be used the other candidates for qPCR analysis if confirm with other reference gene.

It is also valid to emphasize that when we analyze different groups with different interventions, the software will also modify the results. When the NormFinder was used for each analysis groups, the software put genes in a different position and we showed the best combination.

In our study the three software utilized in these analyses produced similar results but the order of the results was not identical and in some cases was considerably different, which corroborate the findings reported by other study [46]. This difference may be attributed to different mathematical models used in each program [24]. On the other hand, there was found similar results for the software geNorm and Normfinder but not for BestKeeper, this can be justified by the fact that this software used the Pearson correlation method to classify the reference genes, a different method compared to the others software [3].

This study is the first to validate reference genes for the evaluation of REx and AAS use effects in different rat tissues. It is important to note that there is no ideal universal reference gene. This work can help you find good candidates, though, for each experiment, species, tissue and other conditions, it is necessary to perform and confirm a specific validation of reference genes, in order to analyze gene expression results more adequately.

\section{Conclusion}

In conclusion, our results do not suggest a specific reference gene for hypothalamus and adrenal gland, since all genes analyzed (Actb, 18s, Hprt1, Tubulin and Gapdh) were stable and suitable for gene expression normalization through qPCR. However, in mesenteric fat tissue, the only suitable reference gene accepted by three software was Tubulin gene.

\section{Competing Interests}

None of the authors has any conflict of interest in submitting this manuscript.

\section{Funding Resource}

This project was supported by: FAPESP (Fundação de Amparo à Pesquisa do Estado de São Paulo \# 2013/05549-0; \# 2013/17587-4), CAPES (Coordenação de Aperfeiçoamento de Pessoal de Nível Superior), CNPq (Conselho Nacional de Desenvolvimento Científico e Tecnológico) and AFIP (Associação Fundo de Incentivo à Pesquisa).

\section{Contribution}

Design and experimental procedures: RP, LF, BFAC and VDA. Data analysis: RP, LF and VDA. Contribution with reagents, materials and analysis tools: RP and VDA. Article writer: RP, LF, BFAC and VD.

\section{Acknowledgements}

The authors would like to thank Vanessa Gonçalves Pereira for English review writing.

\section{References}

1. Bustin SA, Benes V, Garson JA, Hellemans J, Huggett J, et al. (2009) The MIQE guidelines: minimum information for publication of quantitative real-time PCR experiments. Clin Chem 55: 611-622.

2. Lee KS, Alvarenga TA, Guindalini C, Andersen ML, Castro RM, et al. (2009) Validation of commonly used reference genes for sleep-related gene expression studies. BMC Mol Biol 10: 1-45.

3. Julian GS, de Oliveira RW, Perry JC, Tufik S, Chagas JR (2014) Validation of housekeeping genes in the brains of rats submitted to chronic intermittent hypoxia, a sleep apnea model. PLoS One 9: e109902.

4. Alves MJ, Dos Santos MR, Dias RG, Akiho CA, Laterza MC, et al. (2010) Abnormal neurovascular control in anabolic androgenic steroids users. Med Sci Sports Exerc 42: 865-871.

5. Bronson FH (1996) Effects of prolonged exposure to anabolic steroids on the behavior of male and female mice.Pharmacol Biochem Behav 53: 329-334.

6. Farrell SF, McGinnis MY (2003) Effects of pubertal anabolic-androgenic steroid (AAS) administration on reproductive and aggressive behaviors in male rats. Behav Neurosci 117: 904-911.

7. Su TP, Pagliaro M, Schmidt PJ, Pickar D, Wolkowitz O, et al. (1993) Neuropsychiatric effects of anabolic steroids in male normal volunteers. JAMA 269: $2760-2764$.

8. Hall RC, Hall RC (2005) Abuse of supraphysiologic doses of anabolic steroids South Med J 98: 550-555.

9. Scharhag J, Urhausen A, Kindermann W (2003) Anabolic steroid-induced echocardiographic characteristics of professional football players? J Am CollCardiol 42: 588-589.

10. Ogawa K, Sanada K, Machida S, Okutsu M, Suzuki K (2010) Resistance Exercise Training Induced Muscle Hypertrophy Was Associated with Reduction of Inflammatory Markers in Elderly Women. Mediators of Inflammation 2010: 1-7.

11. Teixeira PC, Costa RF, Matsudo SM, Cordas TA (2009) A prática de exercícios físicos em pacientes com transtorno alimentar. Revista de Psiquiatria Clínica 36: $145-152$.

12. MacKenzie MG, Hamilton DL, Pepin M, Patton A, Baar K (2013) Inhibition of myostatin signaling through Notch activation following acute resistance exercise. PLoS One 8: e68743.

13. Kim JS, Park YM, Lee SR, Masad IS, Khamoui AV, et al. (2012) $\beta$-hydroxy$\beta$-methylbutyrate did not enhance high intensity resistance training-induced improvements in myofiber dimensions and myogenic capacity in aged female rats. Mol Cells 34: 439-448

14. Domingos MM, Rodrigues MF, Stotzer US, Bertucci DR, Souza MV et al. (2012) Resistance training restores the gene expression of molecules related to fat oxidation and lipogenesis in the liver of ovariectomized rats. Eur J App Physiol 112: 1437-1444.

15. Tanno AP, das Neves VJ, Rosa KT, Cunha TS, Giordano FC, et al. (2011) Nandrolone and resistance training induce heart remodeling: role of fetal genes and implications for cardiac pathophysiology. Life Sci 89: 631-637.

16. Hruz T, Wyss M, Docquier M, Pfaffl MW, Masanetz S, et al. (2011) RefGenes: identification of reliable and condition specific reference genes for RTqPCR data normalization. BMC Genomics 12:156.

17. Cassilhas RC, Lee KS, Fernandes J, Oliveira MG, Tufik S, et al. (2012) Spatial memory is improved by aerobic and resistance exercise through divergent molecular mechanisms. Neuroscience 202: 309-317.

18. Pereira GB, Prestes J, Leite RD, Magosso RF, Peixoto FS, et al. (2010) Effects of ovariectomy and resistance training on MMP-2 activity in rat calcaneal tendon. Connect Tissu e Res 51: 459-466.

19. Hornberger TA, Farrar RP (2004) Physiological hypertrophy of the FHL muscle following 8 weeks of progressive resistance exercise in the rat. Can J App Physiol 29: 16-31.

20. Pope JR, Katz DL (1988) Affective and psychotic symptoms associated with anabolic steroids use. Am J Psychiatry 145: 487-490. 
Citation: Pozzi R, Fernandes L, Calegare BFA, D’Almeida V (2016) Validation of Reference Genes for qPCR Analysis of Resistance Training and Androgenic Anabolic Steroids on Hypothalamus, Adrenal Gland and Fat Tissue. J Steroids Horm Sci 7: 180. doi: 10.4172/2157-7536.1000180

Page 7 of 7

21. Pozzi R, Fernandes KR, de Moura CF, Ferrari RA, Fernandes KP, et al. (2013) NandroloneDecanoate Induces Genetic Damage in Multiple Organs of Rats. Arch Environ ContamToxicol 64: 514-518.

22. Vandesompele J, De Preter K, Pattyn F, Poppe B, Van Roy N, et al. (2002) Accurate normalization of real-time quantitative RT-PCR data by geometric averaging of multiple internal control genes. Genome Biol. 3: RESEARCH0034.

23. Svingen T, Jørgensen A, Rajpert-De Meyts E (2014) Validation of endogenous normalizing genes for expression analyses in adult human testis and germ cell neoplasms. Mol Hum Reprod 20: 709-718.

24. Dundas J, Ling M (2012) Reference genes for measuring mRNA expression. Theory Biosci 131: 215-223.

25. Martínez-Beamonte R, Navarro MA, Larraga A, Strunk M, Barranquero C, et al. (2011) Selection of reference genes for gene expression studies in rats. J Biotechnol 151: 325-334.

26. An Y, Reimers K, Allmeling C, Liu J, Lazaridis A, et al. (2012) Validation of differential gene expression in muscle engineered from rat groin adipose tissue by quantitative real-time PCR. Biochem Biophys Res Commun 421: 736-742.

27. Dheda K, Huggett JF, Chang JS, Kim LU, Bustin SA, et al. (2005) The implications of using an inappropriate reference gene for real-time reverse transcription PCR data normalization. Anal Biochem 344: 141-143.

28. 283. Liu XH, Wu Y, Yao S, Levine AC, Kirschenbaum A, et al. (2013) Androgens up-regulate transcription of the Notch inhibitor Numb in $\mathrm{C} 2 \mathrm{C} 12$ myoblasts via $\mathrm{Wnt} / \mathrm{\beta}$-catenin signaling to $\mathrm{T}$ cell factor elements in the Numb promoter. J Biol Chem 288: 17990-17998.

29. Li R, Ferreira MP, Cooke MB, La Bounty P, Campbell B, et al. (2015) Coingestion of carbohydrate with branched-chain amino acids orL leucine does not preferentially increase serum IGF-1 and expression of myogenic related genes in response to a single bout of resistance exercise. AminoAcids 47 1203-12013.

30. Koga S, Kojima A, Ishikawa C, Kuwabara S, Arai K, et al (2014) Effects of diet induced obesity and voluntary exercise in a tauopathy mouse model: implications of persistent hyperleptinemia and enhanced astrocytic leptin receptor expression. Neurobiol Dis 71: 180-192.

31. Ebersbach-Silva $P$, Alves T, Fonseca AT, Oliveira MA, Machado UF, et al. (2013) Cigarette smoke exposure severely reduces peripheral insulin sensitivity without changing GLUT4 expression in oxidative muscle of Wistar rats. Arq Bras Endocrinol Metabol 57: 19-26.

32. Shaker OG, Sadik NA (2013) Vaspin gene in rat adipose tissue: relation to obesity-induced insulin resistance. Mol Cell Biochem 373: 229-239.

33. Brännvall K, Bogdanovic N, Korhonen L, Lindholm D (2005) 19-Nortestosterone influences neural stem cell proliferation and neurogenesis in the rat brain. Eur J Neurosci 21: 871-878.

34. Ellefsen S, Vikmoen O, Zacharoff E, Rauk I, Slettaløkken G, et al. (2014)
Reliable determination of training-induced alterations in muscle fiber composition in human skeletal muscle using quantitative polymerase chain reaction. Scand J Med Sci Sports 24: e332-e342.

35. Pekkala S, Wiklund $P$, Hulmi JJ, Pöllänen E, Marjomäki V, et al. (2015) Cannabinoid receptor 1 and acute resistance exercise - In vivo and in vitro studies in human skeletal muscle. Peptides 67: 55-63.

36. Passos E, Pereira CD, Gonçalves IO, Rocha-Rodrigues S, Silva N, et al. (2015) Role of physical exercise onhepatic insulin, glucocorticoid and inflammatory signaling pathways in an animal model of non-alcoholic steatohepatitis. Life Sci 123: 51-60.

37. Tiss A, Khadir A, Abubaker J, Abu-Farha M, Al-Khairi I, et al. (2014) Immunohistochemical profiling of the heat shock response in obese nondiabetic subjects revealed impaired expression of heat shock proteins in the adipose tissue. Lipids Health Dis 13: 106.

38. Stefanetti RJ, Zacharewicz E, Della GP, Garnham A, Russell AP, et al. (2014) Ageing has no effect on the regulation of the ubiquitin proteasome-related genes and proteins following resistance exercise. Front Physiol 5: 30

39. Chen R, Feng L, Ruan M, Liu X, Adriouch S, et al. (2013) Mechanical-stretch of $\mathrm{C} 2 \mathrm{C} 12$ myoblasts inhibits expression of Toll-like receptor 3 (TLR3) and of autoantigens associated with inflammatory myopathies. PLoS One 8: e79930.

40. Marques-Neto SR, Ferraz EB, Rodrigues DC, Njaine B, Rondinelli E, et al. (2014) AT1 and aldosterone receptors blockade prevents the chronic effect of nandrolone on the exercise-induced cardioprotection in perfused rat heart subjected to ischemia and reperfusion. Cardiovasc Drugs Ther 28: 125-135

41. Marqueti RC, Heinemeier KM, Durigan JL, de Andrade Perez SE, Schjerling $P$ et al. (2011) Gene expression in distinct regions of rat tendons in response to jump training combined with anabolic androgenic steroid administration. Eur $\mathrm{J}$ Appl Physiol 112: 1505-1515

42. Ambar G, Chiavegatto S (2009) Anabolic-androgenic steroid treatment induces behavioral disinhibition and downregulation of serotonin receptor messenger RNA in the prefrontal cortex and amygdala of male mice. Genes Brain Behav 8: 161-173.

43. Riedmaier I, Tichopad A, Reiter M, Pfaffl MW, Meyer HH (2009) Influence of testosterone and a novel SARM on gene expression in whole blood of Macaca fascicularis. J Steroid Biochem Mol Biol 114: 167-173.

44. Sun JH, Nan LH, Gao CR, Wang YY (2012) Validation of reference genes for estimating wound age in contused rat skeletal muscle by quantitative real-time PCR. Int J Legal Med 126: 113-120.

45. Li B, Matter EK, Hoppert HT, Grayson BE, Seeley RJ, et al. (2014) Identification of optimal reference genes for QPCR in the rat hypothalamus and intestine for the study of obesity. Int J Obes 38: 192-197.

46. Kim I, Yang D, Tang X, Carroll JL (2011) Reference gene validation for qPCR in rat carotid body during postnatal development. BMC Res Notes 4: 440. 